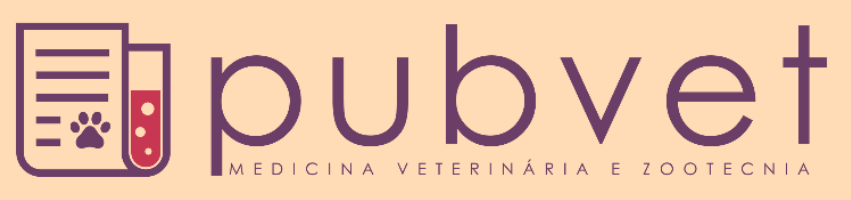

https://doi.org/10.31533/pubvet.v14n2a509.1-4

\title{
Alopecia por diluição da cor em cão da raça yorkshire: relato de caso
}

\author{
Mayara de Carvalho Stelman Gouveia ${ }^{1^{*}}$, Renata Novais Mencalha $^{2} \bullet$, Maria Isabel \\ Osorio Campos Mourão ${ }^{3}$
}

IAluna do curso de Pós Graduação em Clínica de animais de companhia-CESVA-FAA. Valença-RJ Brasil. ${ }^{2}$ Coordenadora do curso de Pós Graduação em Clínica de animais de companhia - CESVA-FAA. Valença-RJ Brasil. ${ }^{3}$ Médica Veterinária-Miguel Pereira-RJ Brasil.E-mail:zooclin_vet@hotmail.com

*Autor para correspondência, E-mail: mayarastelman@gmail.com.

\begin{abstract}
Resumo. A alopecia por diluição da cor é uma doença dermatológica rara, que ocasiona a queda da pelagem preta, sendo conservada a pelagem amarela, e acomete principalmente cães que apresentam pelagem de cor escura, é de etiologia desconhecida, sabe-se que é causada pelo acúmulo de melanina nos pelos. O presente trabalho relata um caso de uma alopecia por diluição da cor, ocorrido em um canino da raça Yorkshire Terrier, de seis meses de idade foi atendido em clínica veterinária particular em Miguel Pereira, Rio de Janeiro que apresentava uma hipotricose na pelagem preta. Foram realizados exames como hemograma e bioquímica, além de tricograma, cultura fúngica e histopatológico. No tricograma pode ver um acúmulo de melanina nos folículos pilosos, e no Histopatológico temos o diagnóstico definitivo. Conclui-se que por ser uma doença rara, e de pouco conhecimento é preciso fazer um diagnóstico através de uma boa anamnese, um tricograma e cultura fúngica, além do histopatológico, fazendo a eliminação de possíveis causas de diagnósticos diferenciais.
\end{abstract}

Palavras chave: dermatológica, histopatológico, pelagem preta

\section{Alopecy for dilution of color in dog of yorkshire breed: case report}

\begin{abstract}
The alopecia by color dilution is a rare dermatological disease that occasionally occurs in black coat and is conserved in yellow coat, and mainly accommodates dogs with dark coat, unknown etiology. It is known what type of melanin hair is in the hair. This paper reports a case of color dilution alopecia, which occurred in a dog Yorkshire Terrier of six month old seen at a private veterinary clinic in Miguel Pereira, Rio de Janeiro, who presented with hypotrichosis in the black coat. Tests were performed such as blood count and biochemistry, in addition to trichogram, fungal culture and histopathology. On the trichogram you can see an accumulation of melanin in the hair follicles, and on histopathology we have the definitive diagnosis. It is concluded that, being a rare disease, and of little knowledge, it is necessary to make a diagnosis through a good anamnesis, and a clinical examination such as trichogram and fungal culture, besides histopathology, eliminating possible causes of differential diagnoses.
\end{abstract}

Keywords: dermatological, histopathological, black hair

\section{Alopecia por dilución de color en un perro Yorkshire Terrier: reporte de caso}

Resumen. La alopecia por dilución de color es una rara enfermedad dermatológica que hace que el pelaje negro se caiga y el pelaje amarillo se conserva. Afecta principalmente a los perros con pelaje oscuro y es de etiología desconocida. Se sabe que es causada por el 
acumulo de melanina en el pelo. Este artículo informa un caso de alopecia por dilución de color, que ocurrió en un canino de Yorkshire Terrier de seis meses de edad atendido en una clínica veterinaria privada en Miguel Pereira, Rio de Janeiro, que presentó hipotricosis en la capa de pelo negro. Se realizaron pruebas como recuento sanguíneo y bioquímica, además de tricograma, cultivo de hongos e histopatología. En el tricograma se puede observar una acumulación de melanina en los folículos capilares, y en el histopatológico tenemos el diagnóstico definitivo. Se concluye que, al ser una enfermedad rara y de poco conocimiento, es necesario hacer un diagnóstico a través de una buena anamnesis, y un examen clínico como tricograma y cultivo de hongos, además de histopatología, eliminando posibles causas de diagnósticos diferenciales.

Palabras clave: dermatológica, histopatológico, capa preta

\section{Introdução}

A alopecia por diluição da cor trata-se de uma doença hereditária, causada pela diferenciação anatômica e acúmulo de melanina no folículo piloso e nas glândulas sebáceas. As displasias foliculares ligadas à cor se assemelham nos quesitos histopatológicos e genéticos, porém clinicamente apresentamse em diferentes formas: a alopecia por diluição da cor (ADC) pode ser observada na forma difusa e a displasia folicular dos pelos pretos (DFPP), na forma localizada (Mecklenburg, 2006; Sawyer et al., 1999). A alopecia por diluição da cor é considerada uma doença dermatológica rara, pode ser encontrada em cães com pelagens escuras, tem um diagnóstico fácil. É uma doença que pode acometer animais que tenham entre 4 e 14 meses, se tornando rara em animais com mais de três anos. Ao início da doença pode notar-se hipotricose, os pelos apresentam-se opacos desprendendo-se facilmente ao toque. $\mathrm{O}$ diagnóstico baseia-se na exclusão de doenças de origem endócrina, fúngica ou parasitária, e tem como confirmação o exame histopatológico.

O objetivo desse trabalho é descrever um caso de alopecia por diluição da cor em cão da raça yorkshire visto que é uma doença rara de ser encontrada na rotina clínica veterinária e de fácil diagnóstico.

\section{Relato de caso}

Uma cadela da raça Yorkshire, de seis meses de idade, foi atendida em uma clínica particular em Miguel Pereira, Rio de Janeiro, com histórico de queda de pelos desde os dois meses de idade. O animal não apresentava nenhuma alteração que pudesse acarretar queda dos pelos, tendo em vista que era vacinado, vermifugado e com controle de ectoparasitas em dia. Apresentava pelos pretos quebradiços e amarelos conservados, como evolução constante nos últimos quatro meses (Figura 1).

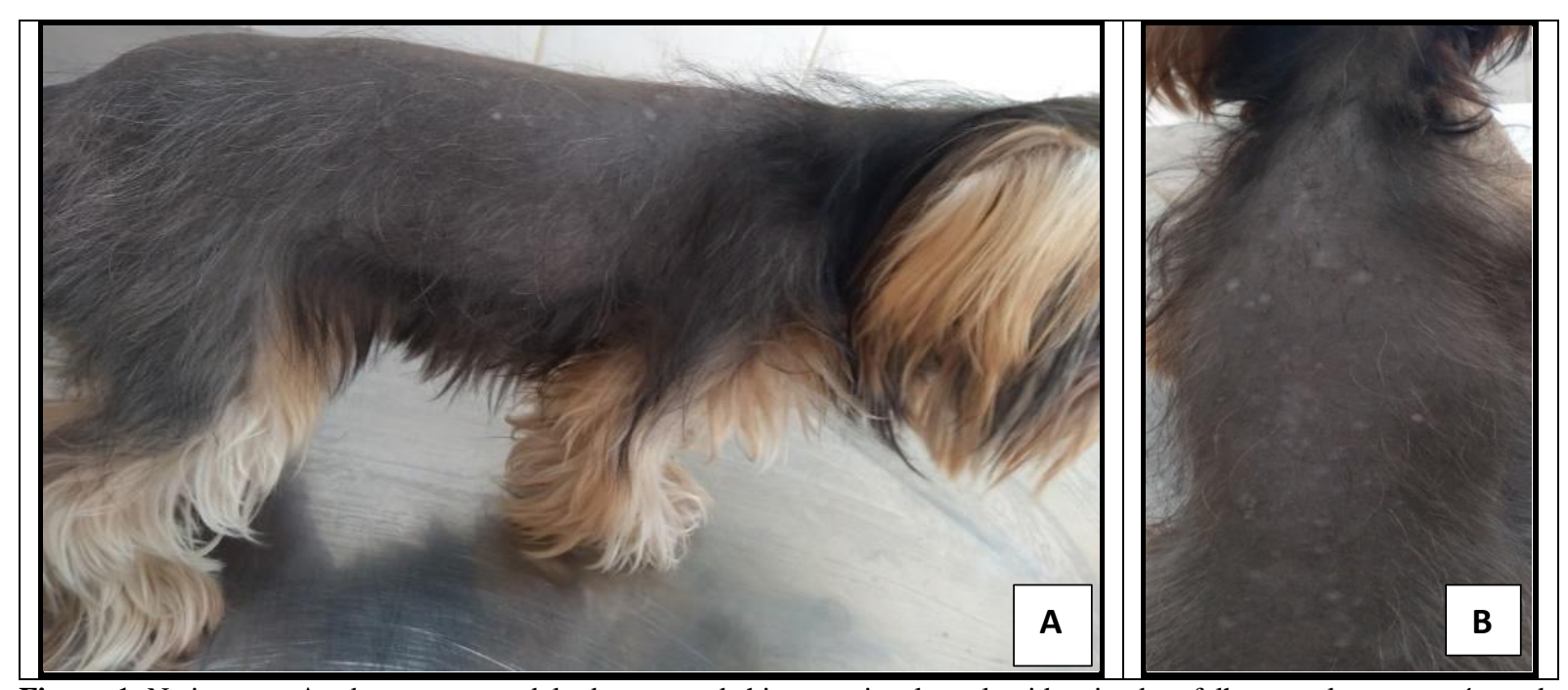

Figura 1. Na imagem A, observa-se a cadela da raça yorkshire em vista lateral evidenciando a falha na pelagem nas áreas de pelos pretos do tronco. Notar a pelagem amarela e branca preservada nas extremidades. Na imagem $\mathbf{B}$, é vista a 
mesma cadela com destaque para a área dorsal do tronco com importante alopecia na área dos pelos pretos, bem como despigmentação multifocal, possivelmente por cicatrização pós piodermite. Acervo: M.Stelman

$\mathrm{Na}$ anamnese, foi relatado pelo tutor que ela começou a apresentar queda dos pelos pretos com 2 meses, e que ela era a única da ninhada que apresentava a queda, o tutor fez controle de ectoparasitas, e não iniciou qualquer outro tratamento.

O animal foi submetido a exames físicos e complementares como hemograma, bioquímica (Ureia, Creatinina, TGO, TGP, Glicose) e tricograma (Figura 2) e cultura fúngica. Após os resultados sem alteração o animal foi submetido a um exame histopatológico, da área afetada. Com o resultado dos exames pode-se confirmar que o animal foi diagnosticado com displasia folicular ligada à cor ou alopecia por diluição da cor.

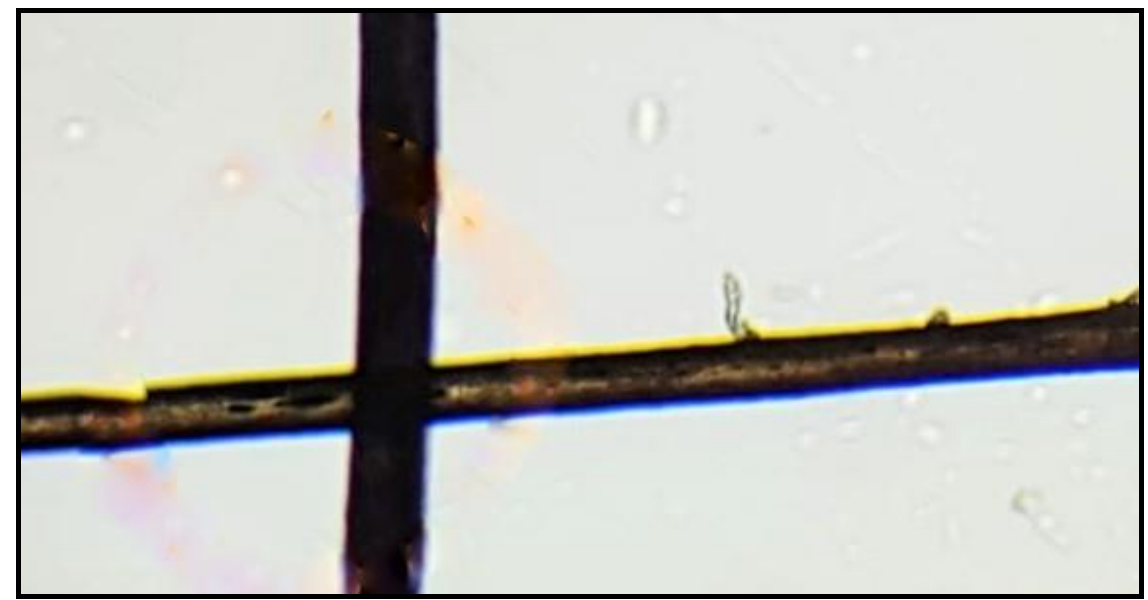

Figura 2: Tricograma realizado para triagem diagnóstica. No pelo horizontal são observados os macromelanossomas ao longo da haste. Aumento de 400X. Acervo: M.Stelman.

\section{Resultados e discussão}

A alopecia por diluição da cor é uma doença dermatológica rara, encontrada principalmente em cães de pelagens azul ou castanho claro raças como Doberman, Pinscher, Dachshund, Yorkshire, Pinscher miniatura e Chow Chow (Clerot \& Oliveira, 2004; Lopes et al., 2017).

A idade para que o animal seja acometido pode variar entre quatro e 14 meses, se tornando raro em animais com mais de três anos. No início pode-se notar hipotricose progressiva, causando uma extensa área de cores diluídas ou pretas. Os pelos irão se apresentar opacos, fraturados, e de fácil desprendimento ao ser tocado, a pele tem excesso de descamação e com foliculite bacteriana secundaria, provocando prurido (Ferreira et al., 2007; Patel \& Forsythe, 2011). A alopecia pode ser completa quando o animal se apresentar com seis a nove meses de idade, embora o tempo de evolução dos sintomas seja variável (Scott et al., 2001). O animal do presente estudo apresentava idade e histórico semelhante ao que foi citado nos trabalhos anteriores, exceto que o animal não apresentou alopecia completa entre os seis meses e os nove meses de idade.

O diagnóstico se baseia no histórico clínico, na anamnese, exame físico, exame histopatológico das lesões cutâneas e o tricograma (exame microscópico do pelo) (Scott et al., 2001). Foram realizados todos os exames para diagnóstico semelhante ao que pode ser observado no estudo, são exames fundamentais para diagnóstico da doença. O exame histopatológico realizado nas áreas de pelagem onde os pelos não são pretos revela normalidade, já nas áreas afetadas, demonstram folículos displásicos, com contornos irregulares, dilatados, e repletos de queratina, com grandes grumos de melanina livre, apresentando hiperqueratose folicular e dermatose atrófica (Lahm et al., 2003; Scott et al., 2001). Foi realizado o exame histopatológico somente da área afetada; porém, o resultado está de acordo com os estes trabalhos.

No exame do Tricograma, a haste pilosa apresenta-se alterada, dificultando a diferenciação entre medula, córtex e cutícula. Podem-se observar também acúmulos irregulares de melanina nas regiões cortical e medular (Ferreira et al., 2007; Leite \& Bicalho, 2012). No Tricograma realizado foram 
observados acúmulos de melanina, e a haste pilosa apresentou alterações, pode-se observar que são as mesmas alterações descritas pelos anteriores auores.

Segundo Scott et al. (2001) Não existe tratamento para alopecia causada pela diluição da cor, o que pode ser feito é tratar as complicações secundárias que são a piodermite, e a descamação e/ou oleosidade. $\mathrm{O}$ animal do presente estudo não apresentava até o momento nenhuma alteração secundária que precisasse ser tratada, ela apresenta uma pele saudável, somente com a pelagem de cor castanha, a tutora foi orientada a não expor a cadela ao sol, fazer uso de roupa protetora e banhos com xampu para proteção da mesma.

\section{Referências bibliográficas}

Clerot, L. L. \& Oliveira, R. (2004). Alopecia por diluição da cor em fêmea yorkshire terrier-relato de caso. Arquivos de Ciências Veterinárias e Zoologias, 7(2):7-23.

Ferreira, R. R., Machado, M. L. S., Aguiar, J., Spanamberg, A., Bianchi, S. P., Oliveira, E. C. \& Driemeier, D. (2007). Displasias foliculares ligadas à cor da pelagem em cães: displasia folicular dos pêlos pretos e alopecia por diluição da cor. Acta Scientiae Veterinariae, 35(1):119-124.

Lahm, M. J. C., Silva, S. R. F. V. \& Fabris, V. (2003). Displasia folicular em cão. Ciência Rural, 33(5):949-951.

Leite, L. M. G. \& Bicalho, A. P. C. V. (2012). Tricograma em cães e gatos revisão de literatura. MEDVEP Dermato, 33(5):298-308.

Lopes, N. L., Peixoto, A. P., Costa, T. S., Pisani, R. B. F., Medeiros, C. M. B. T., Ramadinha, R. H. R. \& Fernandes, J. I. (2017). Alopecia por diluição da cor: relato de caso. Brazilian Journal of Veterinary Medicine, 39(3):198-202.

Mecklenburg, L. (2006). An overview on congenital alopecia in domestic animals. Veterinary Dermatology, 17(6):393-410.

Patel, A. \& Forsythe, P. J. (2011). Dermatologia em pequenos animais. Rio de Janeiro: Elsevier Brasil.

Sawyer, L. S., Moon-Fanelli, A. A. \& Dodman, N. H. (1999). Psychogenic alopecia in cats: 11 cases (1993-1996). Journal of the American Veterinary Medical Association, 21471-74.

Scott, D. W., H., M. W. \& E., G. C. (2001). Mullerand Kirk's small animal dermatology. Philadelphia, USA: WB. Saunders.

Recebido: 21 de novembro, 2019.

Aprovado: 23 de dezembro, 2019.

Publicado: 20 de março, 2020.

Licenciamento: Este artigo é publicado na modalidade Acesso Aberto sob a licença Creative Commons Atribuição 4.0 (CC-BY 4.0), a qual permite uso irrestrito, distribuição, reprodução em qualquer meio, desde que o autor e a fonte sejam devidamente creditados. 